\title{
FATORES RELACIONADOS À NÃO AUTORIZAÇÃO DA DOAÇÃO DE ÓRGÃOS E TECIDOS JUNTO A FAMILIARES QUE RECUSARAM A DOAÇÃO
}

\section{Factors related to the non-authorization of organ and tissue donation by the families who refused organ donation}

\author{
Simey de Lima Lopes Rodrigues ${ }^{1}$, Ilka de Fatima Santana Ferreira Boin², Helder Jose Lessa Zambelli', \\ Luiz Antônio da Costa Sardinha1', Elaine Cristina Ataíde², Marli Elisa Nascimento Fernandes ${ }^{3}$
}

\section{RESUMO}

Objetivo: Caracterizar o processo de diagnóstico de morte encefálica (ME) dos potenciais doadores (PD), compreender as condições e os momentos que as informações dos PD foram relatadas aos familiares em relação às condições clínicas dos PD, do diagnóstico de ME e da entrevista para a doação. Método: Estudo quantitativo, descritivo, exploratório e retrospectivo, com 76 potenciais doadores notificados em 2015, não efetivados devido à recusa familiar, sendo os dados obtidos por meio das informações de prontuários da Organização de Procura de Órgãos do Hospital das Clínicas da Unicamp e submetidos à análise descritiva. Resultados: Predominaram indivíduos brancos (75\%), masculinos (61,8\%), idade entre 20 e 60 anos (78,9\%), casados (42,1\%), hospitalizados nas redondezas de Campinas (47,4\%), acometidos de acidente vascular encefálico $(56,6 \%)$ e assistidos em unidades de terapia intensiva $(77,7 \%)$ e em emergências $(21,1 \%)$. O tempo de internação até o diagnóstico de morte encefálica variou de um a 29 dias, sendo $87,4 \%$ das vezes, esclarecida a morte encefálica aos familiares até 12 horas após o óbito. Quanto às entrevistas, $78,4 \%$ das famílias foram entrevistadas imediatamente após o esclarecimento da morte encefálica; somente $65,2 \%$ destas foram feitos em ambientes privados; $57,9 \%$ por profissionais que atuam na doação; $43,4 \%$ referiam-se a parente de primeiro grau. Entre os motivos para a não doação, destacaram-se: falecido que não era doador (21\%), tempo prolongado para devolver o corpo para o sepultamento $(19,7 \%)$, religioso $(14,5 \%)$ e familiares que não acreditam em morte encefálica (13,2\%). Conclusão: Verificou-se predomínio de PD em leitos intensivos, porém há ainda muitos mantidos nas emergências; a comunicação de morte foi realizada em ambientes não-privados e por profissionais não capacitados, tendo estes influenciado na incidência de não doações.

Descritores: Morte Encefálica; Doação de Órgãos e Tecidos; Transplantes; Recusa de Participação; Acolhimento.

Instituição:

1. Organização de Procura de Órgãos/ Universidade Estadual de Campinas

2. Departamento de Cirurgia da Faculdade de Ciências Médicas/ Universidade Estadual de Campinas

3. Hospital das Clínicas da Unicamp/Universidade Estadual de Campinas

https://doi.org/10.53855/bjt.v24i4.429

Correspondência:

Simey de Lima Lopes Rodrigues

E-mail: simey.lima@gmail.com

Recebido em: 28/12/2020

Aceito em: 02/12/2021

\section{INTRODUÇÃO}

O Brasil vem se destacando nos últimos anos pela criação de um dos melhores programas públicos de transplante do mundo, oferecendo ao cidadão que necessita dessa terapêutica uma assistência holística e gratuita, durante toda a vida, buscando oferecer qualidade no procedimento realizado e melhora da qualidade de vida.

Diante disso, além de todo preparo do potencial receptor para o transplante, com avaliação multiprofissional e exames específicos, da necessidade de serviço hospitalar com equipe cirúrgica e assistencial e 
equipamentos especializados, sabemos que o transplante somente é efetivado com a disponibilidade de órgãos e tecidos.

Sendo assim, sabemos que, para suprir essa demanda de órgãos e tecidos, o Brasil vem melhorando os índices de doação, com aumento do número de doadores e da taxa de notificação de potenciais doadores (PD) em 2017, alcançando, na última década, expressivo aumento no número de transplantes realizados, ${ }^{1}$ se comparados aos anos anteriores. Entretanto, nossos índices referentes ao número de doadores por milhão de população (pmp) ainda são baixos, ficando com menor desempenho quando comparados com países europeus, norte americanos e da América Latina. ${ }^{2}$

Com o desequilíbrio crescente entre a oferta e a demanda de órgão no Brasil ${ }^{1}$ e em países desenvolvidos, ${ }^{3-5}$ os pacientes candidatos a transplantes passam a ter piora em sua condição de saúde com o decorrer dos anos, podendo ir a óbito.

Para aumentar a oferta de órgãos e tecidos é preciso ampliar o número de doações POR MEIO de pacientes que evoluem com morte encefálica (ME), pois nessa condição, o doador pode disponibilizar maior quantidade de órgãos e tecidos ${ }^{3,6}$ e, para efetivar a doação desses pacientes no Brasil, deve-se seguir o rigor do processo de diagnóstico da $\mathrm{ME}$, de acordo com a legislação vigente, ${ }^{7}$ e, em seguida, solicitar a autorização da família ou do responsável legal, sendo essa uma decisão difícil e complexa, que contribui para o não consentimento.

O desconhecimento da ME parece ser tanto da a população quanto dos profissionais de saúde que prestam assistência a potenciais doadores (PD), sendo esse apontado como um dos motivos que levam os familiares a recusar a doação dos órgãos e tecidos de PD em ME, ${ }^{8-10}$ além da insatisfação familiar com a abordagem médica. ${ }^{11,12}$ Os familiares observam que a equipe médica tem pressa em atestar a ME, falam sobre esse diagnóstico e da possibilidade de doação de forma precoce, sem que estes compreendam o estado mortis do seu ente querido, situação agravada com a ausência de suporte psicossocial. ${ }^{13}$

No Brasil, a recusa familiar é a principal causa da não doação, chegando a $70 \%$ em algumas regiões, 1 sendo também elevada em outros países. ${ }^{5,10,11,14-17}$

Sabe-se que o momento correto para entrevistar os familiares para a doação deve respeitar os requisitos legais (após a certificação da ME), a boa relação médico-família e a percepção da equipe de que os familiares não têm qualquer dúvida quanto à evolução clínica de seu ente querido durante a hospitalização e da irreversibilidade da ME por meio dos exames clínicos e complementares que foram realizados. Assim, se a informação sobre o diagnóstico de ME for antecipada aos familiares, (antes da conclusão do estado mortis) isso pode levar à insatisfação e desconfiança do atendimento prestado, além da possibilidade de infração ética do profissional. ${ }^{13}$

Nesse sentido, diagnosticar a dinâmica do processo de diagnóstico de ME e como os familiares foram esclarecidos da condição de seus entes queridos pode elucidar falhas no processo assistencial, pois parte do princípio que o cuidado com as famílias também faz parte da assistência. O desconhecimento dos profissionais sobre os sentimentos dos familiares diante da comunicação da ME e da possibilidade da doação podem levar a sequelas irreparáveis às famílias não doadoras e ao aumento das taxas de recusa à doação. ${ }^{13}$

Diante do elevado índice de recusa familiar (81 casos; 42,7\%) notificadas a Central de Transplante Estadual de São Paulo, no período de 2015, da OPO HC - Unicamp, (maior número absoluto observado de perda anual por esta causa, em relação aos anos anteriores),18 dos estudos que reconhecem a precocidade de informação do diagnóstico de ME como fator negativo para o desfecho da doação. ${ }^{11-13,17,19}$

Este estudo teve como objetivo caracterizar o processo de diagnóstico de ME dos PD, compreender as condições e os momentos em que as informações referentes a eles foram relatadas aos familiares em relação às suas condições clínicas, do diagnóstico de ME e da entrevista para a doação. Espera-se que o diagnóstico das recusas consiga sintonizar ações da OPO com as equipes dos hospitais notificantes para ampliar a satisfação dos familiares de PD com o atendimento oferecido nas instituições de saúde.

\section{MÉTODO}

Trata-se de um estudo quantitativo, descritivo, exploratório e retrospectivo, ${ }^{20}$ iniciado após a aprovação do Comitê de Ética em Pesquisa (CEP), parecer 1.560.999/2016, e baseou-se nos dados dos prontuários físicos dos PD do ano de 2015 da OPO do HC-Unicamp, em que os familiares não optaram pela doação. No ano de 2015, houve 81 casos de recusas familiares. Foram incluídos todos os casos de recusa familiar do ano de 2015, com diagnóstico de ME concluído (n: 76) e excluídos cinco casos que não continham o impresso do Termo de Declaração de ME, nem informações do registro da realização de entrevista familiar com o motivo da recusa, informações mínimas necessárias para o andamento do estudo. 
Simey de Lima Lopes Rodrigues, Ilka de Fatima Santana Ferreira Boin, Helder Jose Lessa Zambelli, Luiz Antônio da Costa Sardinha, Elaine Cristina Ataíde, Marli Elisa Nascimento Fernandes

A coleta de dados foi realizada nos prontuários de 76 PD, nas dependências da OPO, pela pesquisadora, sendo os instrumentos de pesquisa formulados pela mesma, de forma a resgatar o maior número de informações contidas no prontuário, restringindo-se a questões abertas e fechadas para obtenção das variáveis sociodemográficas (estado civil, grau de parentesco, procedência da internação dos PD), e clínicas (idade, raça, sexo, estado civil, causa de ME), características do ambiente de atendimento prestado (unidade de internação, local da entrevista familiar) e do processo de doação. A variação dos tempos do processo de doação foi contabilizada como: Tempo 1 (T1): referiu-se à data da internação hospitalar até a data da ME; Tempo 2 (T2): período entre término do processo de diagnóstico de ME até a data da comunicação à família do paciente com ME; Tempo 3 (T3): momento da conclusão do processo de diagnóstico de ME até a entrevista familiar.

As causas de ME investigadas foram cerebrovasculares, traumáticas e outras (encefalopatia anóxica após parada cardiorrespiratória e tumores primários do Sistema Nervoso Central)..$^{8,11,21-26}$ Os motivos informados da recusa foram acumulados segundo relatos de literatura. . $^{8-12,19,21,24,27-28}$

Os dados obtidos foram transcritos para uma planilha elaborada pela pesquisadora, para facilitar, e transportados para o programa Excel for Windows/2003; em seguida, para o programa Statistical Analysis System (SAS) System for Windows, versão 8.02, para as análises descritivas, sendo confeccionados gráficos, tabelas de frequência, medidas de posição (média, mínima e máxima) e dispersão (desvio-padrão).

\section{RESULTADOS}

Os dados do perfil sociodemográfico e clínico constam na tabela 1 .

Tabela 1: Perfil sociodemográfico e clínico dos Potenciais Doadores da OPO HC-Unicamp. Campinas, SP. 2015

\begin{tabular}{|c|c|}
\hline Variáveis & $(n=76)$ \\
\hline Idade (anos) & $42,2 \pm 16,6$ \\
\hline \multicolumn{2}{|l|}{ Cor da Pele } \\
\hline Branca & $57(75,0 \%)$ \\
\hline Negro & $10(13,2 \%)$ \\
\hline Pardo & $9(11,8 \%)$ \\
\hline Sexo masculino & $47(61,8 \%)$ \\
\hline \multicolumn{2}{|l|}{ Estado Civil } \\
\hline Casado & $32(42,1 \%)$ \\
\hline Solteiro & $24(31,6 \%)$ \\
\hline
\end{tabular}

Tabela 1: (continuação)

\begin{tabular}{lc}
\hline \multicolumn{1}{c}{ Variáveis } & (n=76) \\
\hline União consensual & $8(10,5 \%)$ \\
Divorciado & $5(6,5 \%)$ \\
Viúvo & $3(4,0 \%)$ \\
Não informado & $4(5,3 \%)$ \\
Causa da ME & \\
Cerebrovasculares & $43(56,6 \%)$ \\
Traumatismo Crânio Encefálico & $23(30,3 \%)$ \\
Outras causas & $10(13,1 \%)$ \\
Procedência do Potencial Doador* & \\
Região Metropolitana de Campinas & $36(47,4 \%)$ \\
Vale do Paraíba & $17(22,4 \%)$ \\
Piracicaba, Rio Claro, Bragança Paulista, & $23(30,2 \%)$ \\
Atibaia, Jundiaí, Limeira, Mogi-Guaçu & \\
\hline ME = morte encefálica; & \\
* Fonte: emplasa (https://www.emplasa.sp.gov.br/RMC)
\end{tabular}

Neste estudo, observamos que $75 \%$ dos PD eram brancos, $61,8 \%$ do sexo masculino, $42,1 \%$ casados e $47,4 \%$ residentes na Região Metropolitana de Campinas, com idade 42,2 \pm 16,6 (4 -70) anos, sendo que 78,9\% deles tinham entre 20 e 60 anos.

Dentre as principais causas de ME, destacou-se AVC (56,6\%) e trauma (30,3\%). Constatamos que $77,7 \%$ dos pacientes receberam cuidados nas unidades de terapia intensiva (UTI) e $21 \%$ nas unidades de emergência. Os locais de internação hospitalar, a entrevista familiar para doação e os tempos do processo de doação seguem na Tabela 2.

Detectamos extensa variação entre o tempo de internação e o diagnóstico de ME (de um a 29 dias). O tempo entre a conclusão do processo de diagnóstico de $M E$ até a comunicação da $\mathrm{ME}$, em $87,3 \%$ das vezes, demorou até 12 horas e, somente, $21,1 \%$ dos médicos comunicaram a ME aos familiares imediatamente após a realização desse diagnóstico. Por outro lado, observamos que em $78,4 \%$ das vezes, os familiares foram entrevistados em menos de uma hora após a equipe médica comunicar a ME; $65,2 \%$ foram feitas nas salas das unidades de internação; $57,9 \%$ das vezes por profissionais que atuam na área de doação e em 39,5\%, por outros profissionais (Tabela 2). Dos entrevistados, $43,4 \%$ eram parentes de primeiro grau $(27,6 \%$ eram pais e $15,8 \%$ filhos), $34,2 \%$ cônjuges, $17,1 \%$ parentes de segundo grau (15,8\% por irmãos e 1,3\% avós) e, em $5,3 \%$, não tivemos acesso ao grau de parentesco.

Os motivos para não doação descritos nos prontuários da OPO estão descritos na tabela 3. 
Simey de Lima Lopes Rodrigues, Ilka de Fatima Santana Ferreira Boin, Helder Jose Lessa Zambelli, Luiz Antônio da Costa Sardinha, Elaine Cristina Ataíde, Marli Elisa Nascimento Fernandes

Tabela 2: Locais de internação hospitalar e da realização da entrevista familiar e descritivo das variações dos tempos do processo de doação dos Potenciais Doadores da OPO HC-Unicamp. Campinas, SP. 2015

\begin{tabular}{|c|c|}
\hline Variáveis & $(n=76)$ \\
\hline \multicolumn{2}{|l|}{ Unidades de Internação } \\
\hline Unidade de Terapia Intensiva adulto & $55(72,4 \%)$ \\
\hline Emergência & $16(21,0 \%)$ \\
\hline Unidade de Terapia Intensiva pediátrica & $4(5,3 \%)$ \\
\hline Enfermaria & $1(1,3 \%)$ \\
\hline $\begin{array}{l}\text { Comunicação prévia da abertura do processo de } \\
\text { diagnóstico de ME }(n=67)\end{array}$ & $47(70,1 \%)$ \\
\hline \multicolumn{2}{|l|}{$\begin{array}{l}\text { Profissional que comunicou a abertura do } \\
\text { processo de diagnóstico de ME }\end{array}$} \\
\hline Médico & $40(85,1 \%)$ \\
\hline Enfermeiro & $01(2,2 \%)$ \\
\hline Não informado & $06(12,7 \%)$ \\
\hline $\begin{array}{l}\text { T1 (internação até o diagnóstico de ME - dias; } \\
\mathrm{n}=75 \text { ) }\end{array}$ & $5,7 \pm 4,4$ \\
\hline $\mathrm{T} 1<1$ & $3(4,0 \%)$ \\
\hline $\mathrm{T} 1$ (1 a 2$)$ & $11(14,6 \%)$ \\
\hline T1 (> 2 até 7$)$ & $41(54,7 \%)$ \\
\hline $\mathrm{T} 1(>7)$ & $20(26,7 \%)$ \\
\hline $\begin{array}{l}\text { T2 (conclusão do protocolo até comunicação de } \\
\text { ME - horas; } n=71 \text { ) }\end{array}$ & $5,5 \pm 5,4$ \\
\hline $\mathrm{T} 2<1$ & $15(21,1 \%)$ \\
\hline T2 (1 até 12$)$ & $47(66,2 \%)$ \\
\hline T2 (>12 até 22$)$ & $9(16,7 \%)$ \\
\hline $\begin{array}{l}\text { T3 (comunicação da ME até entrevista familiar - } \\
\text { horas; } n=74 \text { ) }\end{array}$ & $2,5 \pm 4,3$ \\
\hline $\mathrm{T} 3(<1)$ & $58(78,4 \%)$ \\
\hline T3 (> 1 até 6$)$ & $9(12,1 \%)$ \\
\hline $\mathrm{T} 3(>6)$ & $7(9,5 \%)$ \\
\hline \multicolumn{2}{|l|}{ Local da entrevista familiar $(n=72)$} \\
\hline Sala de espera da unidade de internação & $47(65,2 \%)$ \\
\hline Beira do leito & $13(18,0 \%)$ \\
\hline Sala adaptada & $6(8,4 \%)$ \\
\hline $\begin{array}{l}\text { Outros locais (recepção e corredores dos } \\
\text { hospitais) }\end{array}$ & $6(8,4 \%)$ \\
\hline
\end{tabular}

ME = morte encefálica; $T=$ tempo;
Tabela 3: Motivos da recusa familiar para a não doação de órgãos e tecidos

\begin{tabular}{ll}
\hline \multicolumn{1}{c}{ Variáveis } & $\mathbf{n}(\%)$ \\
\hline Falecido não era doador & $16(21,0)$ \\
Tempo prolongado para devolver o corpo & $15(19,7)$ \\
Motivos religiosos & $11(14,5)$ \\
Família não acredita em morte encefálica & $10(13,2)$ \\
Desconhecimento do desejo do falecido & $5(6,6)$ \\
Falta de consenso entre os familiares & $4(5,3)$ \\
Família não respondeu o motivo & $3(4,0)$ \\
Falta de competência técnica da equipe & $3(4,0)$ \\
Falecido doador versus família não doadora & $2(2,6)$ \\
Desconfiança do atendimento prestado & $2(2,6)$ \\
Decisão de um único membro da família & $2(2,6)$ \\
Família não doadora por convicção & $2(2,6)$ \\
Medo da mutilação / integridade corporal & $1(1,3)$ \\
\hline
\end{tabular}

Foram encontrados 12 motivos para a não doação, destacando-se: falecido em vida manifestou que não era doador (21\%), tempo prolongado para a devolução do corpo para o sepultamento $(19,7 \%)$, motivações religiosas $(14,5 \%)$ e familiares que não acreditam no processo da ME (13,2\%), conforme constam na tabela 3 .

\section{DISCUSSÃO}

Considerando-se as características clínicas e sociodemográficas dos $\mathrm{PD}$ elegíveis, em que familiares recusaram a doação na OPO HC-UNICAMP, observamos que nossos dados corroboram os de outros serviços de doação no Brasil e no exterior. ${ }^{8,21-23}$

Houve predomínio de indivíduos brancos, do sexo masculino, adultos, casados e dentro de uma faixa etária economicamente produtiva, ${ }^{8,21-23,26,29} \mathrm{com}$ possível impacto econômico nos lares das famílias que perderam seus entes queridos.

Neste estudo, aproximadamente $50 \%$ dos PD foram hospitalizados na Região Metropolitana de Campinas, o que refere proximidade geográfica da OPO HC-Unicamp com os hospitais notificantes, facilitando a atuação dos profissionais da OPO nesses hospitais em atividades educativas sobre o processo de doação e na realização de entrevistas. 
Simey de Lima Lopes Rodrigues, Ilka de Fatima Santana Ferreira Boin, Helder Jose Lessa Zambelli, Luiz Antônio da Costa Sardinha, Elaine Cristina Ataide, Marli Elisa Nascimento Fernandes

Entre as causas de ME, destaca-se AVC, seguido de causas traumáticas. Esses dados condizem com as taxas de mortalidade do nosso país, sendo que as doenças cerebrovasculares foram a segunda causa de óbito, num total de 100.520 óbitos em $2015,{ }^{30}$ e os óbitos por causas traumáticas cerebrais vêm diminuindo na última década, ${ }^{8,11,21-25}$ podendo ser explicados pela maior preocupação nacional com a morbimortalidade por acidentes de trânsito, favorecendo a intensificação das leis de trânsito vigentes no país. ${ }^{24,31}$ Esses diagnósticos exigem das equipes transplantadoras maior acurácia na avaliação dos órgãos para transplantes.

As UTI destacaram-se como local de internação dos PD; entretanto, encontrou-se um número considerável de indivíduos nas unidades de emergência. É notável a falta de leitos intensivos nos serviços públicos de saúde para atender à demanda necessária, ${ }^{32}$ persistindo um expressivo número de pacientes graves no setor de urgência, descaracterizando esse serviço de seu atendimento inicial, que, atualmente comporta unidades superlotadas, tornando fragilizada a assistência prestada, ${ }^{33}$ não sendo o melhor local para manter os PD. Pesquisadores encontraram taxas aproximadas de $30 \%$ de PD internados nas unidades de emergência, ${ }^{22,25}$ sendo um indicador negativo no processo de doação, pois PD requerem cuidados intensivos, equipe multiprofissional, orientações e esclarecimentos sobre todas as fases do atendimento aos familiares, sendo todas essas etapas essenciais para o processo de doação, e que, muitas vezes, não se consegue no atendimento prestado nas unidades de emergência.

Neste estudo, houve preocupação com os dois extremos encontrados: diagnóstico de ME precoce (quase $20 \%$ da amostra deste estudo, com menos de dois dias de internação, e em 4\% destes, com menos de 24 horas), e tardio, (26,7\%, com constatação de ME entre oito a 29 dias, predispondo os PD a risco de infecção, instabilidade hemodinâmica e piora da funcionalidade dos enxertos). Pesquisadores constataram que, aproximadamente, $60 \%$ dos diagnósticos de ME foram determinados em até dois dias de internamento; destes, $24,4 \%$ com um dia e $4,25 \%$, com cinco dias. ${ }^{9}$

A resolução do Conselho Federal de Medicina (CFM) vigente no momento deste estudo para a constatação da ME era a 1.480/1997 ${ }^{34}$ não informava o tempo mínimo que um paciente deveria ter de internação para que se iniciasse o processo de diagnóstico de ME, pois, tecnicamente, havia diretrizes e recomendações que, ao serem seguidas, asseguravam o diagnóstico de ME sem gerar dúvida de reversibilidade. ${ }^{35}$ Porém, após 20 anos da resolução do CFM 1.480/1997, ${ }^{34}$ a legislação técnica tem se aprimorado, tendo publicado uma nova resolução
(CFM 2.173/2017),7 contemplando o tempo mínimo de internação, de acordo com a causa da ME, oferecendo mais segurança para os profissionais médicos para realizarem os exames de constatação da ME.

Quando os familiares são esclarecidos da gravidade do quadro clínico e do risco de morte do paciente, passam a ter maior confiança na equipe, ou seja, quando percebem que o atendimento é adequado e os profissionais estão empenhados no tratamento do paciente, consideram satisfatória a assistência prestada durante a internação do paciente. Assim, quando os familiares percebem que todos os recursos materiais e humanos necessários à tentativa de recuperação do paciente foram utilizados, há sensação de conforto e a angústia da família é amenizada. ${ }^{36}$ Há descrença das famílias doadoras em relação ao quadro de $\mathrm{ME}$ de seus entes queridos comunicado pelo médico, indicando possíveis lacunas no esclarecimento da ME a elas. ${ }^{37}$

A observação desses cuidados, tanto de ordem técnica quanto humanística, permite afirmar que quando o processo de doação inicia-se em um período de menos de 24 horas de internação, mesmo com respaldo da legislação para iniciar o diagnóstico de $\mathrm{ME}$, pode transparecer aos familiares a sensação de que a equipe médica assistencial não se empenhou em fazer todos os procedimentos necessários para manter vivo seu ente querido e esse desconforto pode contribuir para a dúvida no atendimento prestado e no diagnóstico de ME. Por outro lado, diagnóstico de ME tardio pode levar a maiores riscos de perdas dos PD, bem como favorecer um desgaste físico e emocional nos familiares.

Quanto ao tempo entre a data e a comunicação da ME, na maioria das vezes, a informação não foi transmitida aos familiares no momento da constatação de morte, levando, em alguns casos, até 26 horas para ser retratada às famílias. Acreditamos que o esclarecimento da $\mathrm{ME}$ deva ser realizado imediatamente após a constatação do diagnóstico, visto que os familiares terão tempo maior para assimilar a ME. A atuação de assistentes sociais na convocação desses familiares auxilia nas dificuldades sociais e econômicas que possam ser impeditivas para que a família esteja presente no hospital naquele momento. ${ }^{37-38}$

Notou-se neste estudo que a maioria das entrevistas para doação $(62,2 \%)$ foi realizada imediatamente após a comunicação do diagnóstico de ME, pelo que podemos deduzir que a maioria das famílias não teve tempo necessário para a compreensão da ME e reflexão sobre a possibilidade da doação. 
Estudos apontam que, mesmo quando os familiares são favoráveis à doação, um fator impeditivo pode ser o fato de se sentirem sobrecarregados com a notificação da morte imediatamente seguida do pedido de consentimento. ${ }^{10}$ Trata-se de um processo de decisão complexo, pois um limite de tempo para tomar a decisão de doar ou não doar cria a sensação de urgência, além de, quando a solicitação do consentimento para a doação é realizada imediatamente após a comunicação de ME dificultar o foco do pedido, porque nesse momento as famílias estão sofrendo com a constatação da morte..$^{19}$

O predomínio das entrevistas realizadas em salas de espera das unidades $(65,2 \%)$ pode ser interpretado como um fator favorável à doação, pois trata-se de um local privativo, minimizando a interrupção da conversa existente entre familiares e profissionais, permitindo que os familiares sejam ouvidos e possam vivenciar situações emocionais intensas sem que se sintam constrangidos ou coagidos. Os demais espaços, como beira do leito, salas adaptadas, corredor e recepção do hospital sugerem que estes foram utilizados devido à inexistência de salas de espera nas unidades, e às vezes, podem remeter à falta de conscientização dos profissionais de saúde. Esses achados já foram contemplados em outros estudos ${ }^{8,27}$ e os autores orientaram sobre a necessidade de maiores investimentos na estrutura hospitalar, seja física, material ou mesmo em recursos humanos, para melhorar a efetivação dos PD. ${ }^{39}$

A maioria das entrevistas foi realizada por profissionais com experiência em doação, porém ainda foram insuficientes, pois $40,5 \%$ delas não foram feitas por equipe especializada, tendo sido encontrados resultados semelhantes na literatura. ${ }^{8} \mathrm{~A}$ atuação de profissionais que trabalham com doação pode ter um impacto positivo nas taxas de consentimento familiar. ${ }^{19,40}$ A participação de enfermeiros coordenadores de doação foi vista como positiva, tendo sido retratados como indivíduos carinhosos, dando apoio e informação sobre a condição de seu parente e do processo de aquisição de órgãos; por outro lado, familiares disseram estar insatisfeitos com a falta de oportunidade de participar das decisões relativas ao cuidado de seu ente querido, falta de conhecimento e esclarecimento da equipe médica sobre o tratamento adotado e dos testes para diagnótico de ME, deixando-os desapontados. ${ }^{12,40}$

Em relação aos índices de doação, os países têm adotado políticas públicas multifacetadas, destacandose a coordenação intra-hospitalar para doação, educação dos profissionais que trabalham em unidades hospitalares de pacientes críticos, atenção aos meios de comunicação de massa com vistas à educação da população e incentivo financeiro aos hospitais para atividades de doação. ${ }^{41}$ Diante disso, esperamos maiores investimentos governamentais com divulgação das temáticas de ME e doação de órgãos à população, além dos profissionais que atuam na doação, neste estudo representados pelos profissionais da OPO HC-Unicamp, atuarem diretamente nos hospitais de sua área de abrangência, para capacitação das equipes assistências e da doação local (Comissão Intra-Hospitalar de Doação de Órgãos e Tecidos para Transplantes- CIHDOTT).

Pesquisadores têm buscado compreender qual é o membro familiar com maior tendência à recusa, ${ }^{8,23}$ não tendo sido encontrado na literatura consenso sobre essa variável. Assim, constataram menor favorabilidade à doação entre cônjuges e filhos e maior propensão a doar entre os pais. ${ }^{23}$ Se considerarmos que houve significante estatística nessas variáveis, ${ }^{23}$ faz-se necessária a dispensa de cuidados adicionais quando os parentes entrevistados forem pais e cônjuges de PD da área de abrangência da OPO HCUnicamp.

A principal causa para a não doação foi "falecido não era doador" e, em apenas dois casos, os familiares optaram pela recusa, mesmo sabendo que o falecido gostaria de ser doador. A falta de conhecimento prévio e opiniões do falecido podem contribuir para a recusa do consentimento à doação, ${ }^{11}$ porém, mesmo quando as famílias conhecem a preferência explícita do falecido em doar, nem sempre consentem, atribuindo a decisão de não doar a fatores contextuais, como mal momento do pedido, família sobrecarregada, apoio insuficiente de outros parentes ou profissionais de saúde, pouco conhecimento adquirido na internação sobre a doação de órgãos. ${ }^{10}$

O "tempo prolongado para devolver o corpo aos familiares para o sepultamento" foi a segunda causa de recusa deste estudo, sendo esse motivo impactante em outros estudos. ${ }^{8,9}$ Durante a entrevista, familiares solicitam informações sobre o tempo dos procedimentos de retirada dos órgãos, para que eles possam organizar a cerimônia fúnebre. Os profissionais da doação informam uma estimativa de 24 horas, esclarecendo os procedimentos que são necessários para a validação dos PD com segurança e dentro dos princípios éticos. ${ }^{8}$ Entretanto, muitas famílias optam pela não doação, alegando ser um tempo longo, que prolonga o sofrimento. No estudo de Groot et al. (2016), familiares de doadores requisitaram aos profissionais maiores esclarecimentos da duração dos procedimentos, sendo o tempo do procedimento de doação avaliado como negativo por falta dessa informação. ${ }^{10}$ 
Simey de Lima Lopes Rodrigues, Ilka de Fatima Santana Ferreira Boin, Helder Jose Lessa Zambelli, Luiz Antônio da Costa Sardinha, Elaine Cristina Ataide, Marli Elisa Nascimento Fernandes

AU convicção dos familiares de PD em milagres, ratifica nossa tradição judaico-cristã. Outros estudos também identificaram a recusa familiar por motivos religiosos, ${ }^{8,9,11,12,21,27}$ porém, nenhuma religião posicionase de modo absoluto contrária à doação, mas a crença da morte relacionada à parada cardíaca e os rituais ligados ao corpo do falecido limitam a possibilidade de adesão à doação. ${ }^{28}$ Assim, as crenças culturais têm maior impacto que as religiosas, ${ }^{27}$ ou seja, a crença de que, enquanto os batimentos cardíacos não cessam, há chances de Deus realizar um milagre e a condição do parente ser revertida, ${ }^{27}$ demonstrando que, culturalmente, o conceito de ME é pouco aceito em nossa sociedade.

O desconhecimento da sociedade sobre o conceito de ME ${ }^{8,9,12,21,27,29}$ retrata que nos foi apresentando um único modelo de morte - a de coração parado. Os critérios de morte nas mentes das famílias não coincidem com os critérios médicos atuais, dificultando a aceitação de ME. ${ }^{11}$ As recusas por "falta de competência técnica" referiram-se às dificuldades encontradas pela equipe assistencial para esclarecer as demandas da família, tanto no diagnóstico de $\mathrm{ME}$, quanto em relação à doação. Quando relatada a ME para a família, muitas vezes, os profissionais de saúde não percebem que o conceito não foi compreendido por ela, que está em um momento de dor e assimilação da morte, e assim, obedecem somente a uma sequência técnica a ser passada aos familiares e realizam o pedido de doação, ${ }^{10}$ seguido muitas vezes, de uma resposta negativa.

Neste estudo, se considerarmos que os familiares tiveram pouco tempo para assimilar o conceito de ME (menos de uma hora, visto que as entrevistas para doação foram seguidas da comunicação da ME), além do grande percentual destas terem sido realizadas por equipes que não pertencem à doação, podemos afirmar que parte dessas recusas poderia ter sido evitada.

A "desconfiança do atendimento prestado" pode gerar descontentamento para a família e deve ser um indicador da existência de falha no atendimento prestado. Assim, é necessário que os profissionais tenham competência técnica para atendimento de PD, construam uma relação de confiança com a família, minimizando os anseios e dúvida dos parentes, pois pesquisadores apontam que esse descontentamento pode ser evitado se a família é convidada a participar das possibilidades terapêuticas existentes.10 Quanto aos termos legais, a legislação brasileira é protetiva à família, assegurando aos familiares de PD a indicação de um médico de sua confiança para acompanhar os exames de constatação de $M E,{ }^{42}$ permitindo maior participação dos familiares, mesmo que indiretamente, na constatação de ME.
O "medo de mutilação ou deformidade do corpo", que interfira na crença ou nos rituais funerários, também foi relatado em outros estudos. ${ }^{8,9,11,12,19,24}$ Assim, durante a entrevista, os familiares devem ser esclarecidos de que o corpo do falecido será tratado com respeito, assegurando sua reconstituição de forma condigna para o sepultamento, sendo essa pactuação garantida por lei. ${ }^{42}$

A literatura aponta tendência à recusa quando a decisão de doar está dependendo de um único membro da família, ou quando há membros na família que divirjam sobre a doação, ${ }^{10}$ pois familiares favoráveis à doação desconsideram a sua intenção de doar por medo da repressão por parte de outro membro da família. ${ }^{24}$

Portanto, este estudo detectou os motivos alegados pelos familiares de $\mathrm{PD}$ à não doação de órgãos e tecidos e constatou falhas no atendimento prestado, tanto para esclarecimento do diagnóstico de $\mathrm{ME}$, quanto para a realização da entrevista familiar.

Como limitações do estudo, as análises foram baseadas no relato dos profissionais das instituições hospitalares à OPO, e não da observação direta do pesquisador, não sendo possível identificar a qualificação em relação à doação desses profissionais que atuaram no processo. Sugerimos estudos observacionais de campo e aqueles com correlação para verificar a efetivação da doação por profissionais que atuam ou não na doação, bem como mensuração da interferência de ações educativas no atendimento prestado e aquelas que avaliem a interferência das estruturas físicas hospitalares nesse processo.

\section{CONCLUSÃO}

Verificou-se elevado número de $\mathrm{PD}$ internados em unidades de emergências, em hospitais inseridos nas proximidades da OPO. Constatou-se a prática do diagnóstico de ME precoce, comunicação tardia do diagnóstico e predomínio de entrevistas familiares imediatamente após a comunicação da ME, diminuindo o tempo dado aos familiares para assimilar o conceito de ME e elaboração do luto, dificultando o consentimento à doação. Considerável número de entrevistas foi realizado em ambientes não privativos, por profissionais que não pertencem à equipe de doação, sendo quase todos os motivos alegados para recusa passíveis de ações educativas, muitas vezes, realizadas na população quando vivenciam a perda de um familiar por ME. Outros estudos devem ser realizados por meio de análises comparativas, para maior robustez dos dados constatados, corroborando para melhor condução dos casos de ME e no acolhimento das famílias. 


\section{ABSTRACT}

Purpose: To characterize the care provided to potential donors eligible for donation and their families, and to understand why family members refuse organ and tissue donation. Method: Quantitative, descriptive, exploratory, and retrospective study, with 76 potential donors notified in 2015, whose donation was not carried out due to family refusal. Data was obtained from medical records of the Organ Search Organization at Hospital de Clínicas from Unicamp, and submitted to descriptive analysis. Results: There was a predominance of white individuals (75\%), male $(61.8 \%)$, with ages between 20 and 60 years (78.9\%), married (42.1\%), hospitalized in the vicinity of Campinas (47.4\%), affected by stroke $(56.6 \%)$ and assisted in intensive care units $(77.7 \%)$. The length of hospital stays until the diagnosis of brain death ranged from one to 29 days. In $87.4 \%$ of cases brain death was explained to family members up to 12 hours after death. As to the interviews, $78.4 \%$ of families were interviewed immediately after the clarification of brain death; only $65.2 \%$ of these were performed in private environments; $57.9 \%$ by professionals working in the donation; $43.4 \%$ to a first-degree relative. Among the reasons for not donating, the following prevailed: the deceased was not a donor $(21 \%)$, extended time to return the body for burial $(19.7 \%)$, religious reasons $(14.5 \%)$, and family members who do not believe in death brain (13.2\%). Conclusion: It was verified predominance of PD in intensive care beds, but there are still many kept in emergency rooms, communication of the brain death performed in non-private environments, and made by non-capable professionals, and these influenced the incidence of non-doors.

Keywords: Brain Dead; Tissue and Organ Procurement; Transplants; Refusal to Participate; User Embracement.

\section{REFERÊNCIAS}

1. Dimensionamento dos Transplantes no Brasil e em cada estado (2010-2017). Registro Brasileiro de Transplantes. 2017; 23(4). [acesso em 10 de março 2017]. Disponível em: http://www.abto.org.br/abtov03/Upload/file/RBT/2017/rbtimprensa-leitura-compressed.pdf

2. International Registry in Organ Donation and Transplantation (IRODaT). Worldwide Actual Deceased Organ Donors 2016 (pmp). [cited 2017 Dez 15]. http://www.irodat.org

3. United States of America (USA). Departament of Health \& Human Services. Organ Donation Statistics, 2018. [cited 2018 Jan 21]. https://organdonor.gov/statistics-stories/ statistics.html

4. Eurotransplant International Foundation (Eurotransplant). Statistics Report Library - Active waiting list (at year-end) in all et, by year, by country, by organ 2018. [cited 2018 Feb 23]. http://statistics.eurotransplant.org/

5. NHS Blood and Transplant. Taking organ transplantation to 2020: a detailed strategy. [cited 2018 Feb 23]. http://www. nhsbt.nhs.uk/to2020/the-strategy/

6. Thomson EM, McKeown DW. Organ donation and management of the potential organ donor. Anaesth Intensive Care Med. 2012;13(6):252-8.

7. Brasil. Conselho Federal de Medicina. Resolução $n^{\circ} 2.173$, de 2017. Define os critérios para diagnóstico de morte encefálica. Brasília, DF, Publicada no D.O.U., seção I, p. 2746, 15 de dezembro. 2017.
8. Pessoa JLE, Schirmer J, Roza BA. Avaliação das causas de recusa familiar a doação de órgãos e tecidos. Acta Paul Enferm. 2013;26(4):323-30.

9. Rosário EM, Pinho LG, Oselame GB, Neves EB. Recusa familiar diante de um potencial doador de órgãos. Cad. Saúde Colet. 2013 Rio de Janeiro;21(3):260-6.

10. Groot J, Hoek M, Hoedemaekers C, Hoitsma A, Schilderman $\mathrm{H}$, Smeets $\mathrm{W}$, et al. Request for organ donation without donor registration: a qualitative study of the perspectives of bereaved relatives. BMC Medical Ethics. 2016;17:38.

11. Can F, Hovardaoglu S. Organ donation: a comparison of donating and nondonating families in Turkey. Transplant Proc. 2017 Nov;49(9):1969-74.

12. Lira GG, Pontes CM, Schirmer J, Lima LS. Ponderações de familiares sobre a decisão de recusar a doação de órgãos. Acta Paul Enferm. 2012;25(Especial 2):140-5.

13. Rodrigues SLL. Recusa para doação de órgãos e tecidos na perspectiva da família. Campinas (SP); Tese [Doutora em Ciências]. Universidade Estadual de Campinas; 2019. Disponível em: http://repositorio.unicamp.br/ jspui/bitstream/REPOSIP/333793/1/Rodrigues_ SimeyDeLimaLopes_D.pdf

14. Canadian Transplant Society (Cantransplant). Facts. Update 2014. [cited 2018 Feb 23]. http://www. cantransplant.ca/home/ 
Simey de Lima Lopes Rodrigues, Ilka de Fatima Santana Ferreira Boin, Helder Jose Lessa Zambelli, Luiz Antônio da Costa Sardinha, Elaine Cristina Ataíde, Marli Elisa Nascimento Fernandes

15. United States of America (USA). Department of Health \& Human Services. Organ Donation Statistics. Update August 2017. [cited 2018 Feb 23]. https://organdonor.gov/statisticsstories/statistics.html\#glance

16. Tackmann E, Dettmer S. Acceptance of post-mortem organ donation in Germany: representative cross-sectional study. Anaesthesist. 2018 Feb;67(2):118-25.

17. Bahrami A, Khaleghi E,Vakilzadeh AK, Afzalaghaee M. Process and barriers to organ donation and causes of brain death in northeast of Iran. Electron Physician. 2017 Feb;9(2):3797-3802.

18. Secretaria de Estadual da Saúde do Estado de São Paulo. Sistema Estadual de Transplantes. Distribuição de notificações e número de órgãos disponibilizados e transplantados por OPO. 2015. Acesso em: 02 de Fevereiro de 2016. Disponível em: http://ctxses.saude.sp.gov.br/

19. Groot J, van Hoek M, Hoedemaekers C, Hoitsma A, Smeets W, Vernooij-Dassen $M$, et al. Decision making on organ donation: the dilemmas of relatives of potential brain dead donors. BMC Medical Ethics. 2015;16:64.

20. Gil AC. Como elaborar projeto de pesquisa. $4^{a}$ ed. São Paulo: Atlas; 2002.

21. Dalbem GG, Caregnato RCA. Doação de órgãos e tecidos para transplantes: recusa das famílias. Texto Contexto Enferm. 2010 Florianópolis, Out-Dez;19(4):728-35.

22. Freire ILS, Vasconcelos QLDAQ, Araújo RO, Melo GSM, Costa IKF, Torres GV. Perfil de potenciais doadores segundo a efetividade da doação. Rev Enferm UFSM. 2013;3(Esp.):709-18.

23. Shah MB, Valery Vilchez V, Goble A, Daily MF, Berger JC, Gedaly R, et al. Socioeconomic factors as predictors of organ Donation. Journal of surgical research. Jan 2018;(221):88-94.

24. Moraes EL, Silva LB, Moraes TC, Paixão NC, Izumi NM, Guarino AJ. The profile of potential organ and tissue donors. Rev Latinoam Enferm. 2009;17(5):716-20.

25. Fusco CC, Marcelino CAG, Araújo MN, Ayoub AC, Martins CP. Perfil dos doadores efetivos de múltiplos órgãos e tecidos viabilizados pela organização de procura de órgãos de uma instituição pública de cardiologia. JBT J Bras Transpl. 2009;12:1109-12

26. Rodrigues SLL, Ferraz Neto JB, Sardinha LA, Araujo S, Zambelli HJL, Boin IFFS, et al. Perfil de doadores efetivos do serviço de procura de órgãos e tecidos. Rev Bras Ter Intensiva. 2014;26(1):21-7.

27. Moraes EL, Massarollo MCKB. Recusa de doação de órgãos e tecidos para transplante relatados por familiares de potenciais doadores. Acta Paul Enferm. 2009;22(2):131-5.

28. Ferrazzo S, Vargas MAO, Mancia JR, Ramos FRS. Crenças religiosas e doação de órgãos e tecidos: revisão integrativa da literatura. R. Enferm. UFSM 2011 Set/Dez;1(3):449-60.

29. IBGE. População Economicamente ativa - PEA - 2002 - 2016. [acesso em 8 de março 2017]. Disponível em: https://ww2.ibge.gov.br/home/estatistica/indicadores/ trabalhoerendimento/pme_nova/defaulttab_hist.shtm
30. DATASUS. Mortalidade - Brasil. Óbitos por ocorrência por Região segundo Causa - CID - BR - 10 - Período: 2015. Doenças do aparelho circulatório. Doenças cerebrovasculares. [acesso em: 18 de fevereiro de 2018]. Disponível em: http://tabnet.datasus.gov.br/cgi/tabcgi. exe?sim/cnv/obt10uf.def

31. Brasil. Ministério da Saúde. Secretaria de Políticas de Saúde. Coordenação do Projeto de Promoção da Saúde. Projeto de redução da morbimortalidade por acidente de trânsito: mobilizando a sociedade e promovendo a saúde / Secretaria de Políticas de Saúde, Coordenação do Projeto de Promoção da Saúde. - 2. ed. revista. - Brasília: Ministério da Saúde, 2002.

32. Associação de Medicina Intensiva Brasileira (AMIB). Censo AMIB 2016. [acesso em 09 de março 2018]. Disponível em: http://www.amib.com.br/pdf/Analise_de_Dados_

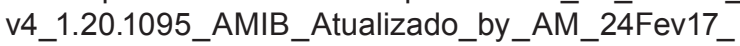
TemplateAMIB.pdf

33. Bittencourt RJ, Hortale VA. Intervenções para solucionar a superlotação nos serviços de emergência hospitalar: uma revisão sistemática. Cad. Saúde Pública. 2009;25(7):1439-54.

34. Brasil. Conselho Federal de Medicina. Resolução $n^{\circ} 1.480$, de 1997. Critérios para diagnóstico de morte encefálica. Brasília, DF, Publicada no D.O.U., p. 18.227, 21 de agosto. 1997.

35. Westphal GA, Garcia VD, Souza RL, Franke CA, Vieira KD, Birckholz VRZ, et al. Diretrizes para avaliação e validação do potencial doador de órgãos em morte encefálica. Rev Bras Ter Intensiva. 2016;28(3):220-55.

36. Santos MJ, Massarollo MC. Processo de doação de órgãos: percepção de familiares de doadores cadáveres. Rev LatinoAm Enferm. 2005;13(3):382-7.

37. Fernandes MEN, Bittencourt ZZLC, Boin IFSF. Vivenciando a doação de órgãos: sentimentos de familiares pós consentimento. Rev. Latino-Am Enferm. 2015;23(5):895-901.

38. Rodrigues SLL et al. Falhas observadas no atendimento de doadores não efetivos e necessidades psicossociais apontadas por seus familiares: por que eles não doaram? J Bras Transpl. 2020;23(3):13-20. Disponível em: https://site. abto.org.br/publicacao/vol-23-no-3/

39. Freire ILS, Vasconcelos QLDAQ, Melo GSMM, Torres GV, Araújo EC, Francisco Arnoldo, et al. Facilitadores e barreiras na efetividade da doação de órgãos e tecidos Texto Contexto Enferm, Florianópolis. 2014 Out-Dez;23(4): 925-34.

40. Manuel A, Solberg S, MacDonald S. Organ Donation Experiences of Family Members. 2010; Nephrol Nurs J. 2010 May-Jun;37(3):229-36.

41. International approaches to organ donation reform. Update November. 2013. [cited 2018 Feb 23]. Available in: http:// www.donatelife.gov.au/sites/default/files/files/OTA_Fact_ Sheets_-_International_approaches_to_organ_donation_ reform_November_2013.pdf

42. Brasil. Lei n. 9434, de 4 de fevereiro de 1997, que dispõe sobre a remoção de órgãos, tecidos e partes do corpo humano para fins de transplante e tratamento, e da outras providências. Diário Oficial da República Federativa do Brasil, Brasília (DF); 1997 p. 13739. 